\title{
Análise comparativa das soluções dos programas de governo para melhoria da mobilidade da Rocinha'
}

\section{Comparative analysis of the solutions of the government programs for improving mobility of Rocinha}

\section{Brandão, Rosana Gouveia'; Bonifácio, Isabela Mara da Silva Conceição2; Alves, Rosane Martins ${ }^{3}$}

\begin{abstract}
1 Programa de Engenharia Urbana, UFRJ, rosanagouveia@poli.ufrj.br 2 Programa de Engenharia Urbana, UFRJ, isabelabonifacio@poli.ufrj.br 3 Programa de Engenharia Urbana, UFRJ, rosane.alves@poli.ufrj.br
\end{abstract}

\begin{abstract}
RESUMO
Os assentamentos subnormais são realidade no contexto da urbanização brasileira, principalmente devido aos processos de crescimento desordenado aliado à falta de investimento em infraestrutura. Na cidade do Rio de Janeiro, tal processo foi intensificado e amparado por políticas públicas. Nesta conjuntura se enquadra o bairro da Rocinha, que só foi reconhecido formalmente como tal no ano de 1993, e a partir dos anos 2000, passou a ser contemplado por grandes projetos públicos como o Plano Diretor da Rocinha, a primeira fase do Programa de Aceleração do Crescimento (PAC) e a proposição de uma segunda fase do PAC. O presente estudo tem como objetivo analisar comparativamente as soluções de mobilidade e acessibilidade adotadas pelos planos em questão, com destaque às soluções do teleférico e do plano inclinado. Essa análise foi realizada por meio da comparação de dados dos equipamentos urbanos e do uso da ferramenta ArcGIS, que possibilita a sobreposição de indicadores, para uma avaliação mais completa dos cenários propostos. De acordo com as observações realizadas, conclui-se que os planos inclinados se mostram mais aderentes às necessidades da comunidade.
\end{abstract}

Palavras-chave: Rocinha, Mobilidade, PAC, Programa de Aceleração do Crescimento.

\section{ABSTRACT}

Subnormal settlements are a reality in the context of Brazilian urbanization, mainly due to the processes of disorderly growth coupled with the lack of investment in infrastructure. In the city of Rio de Janeiro, this process was intensified and supported by public policies. At this juncture, the Rocinha neighborhood, which was formally recognized as such only in the year of 1993, and since 2000 was contemplated by major public projects such as the Rocinha Master Plan, the first phase of the Growth Acceleration Program (Programa de Aceleração do Crescimento - PAC) and the proposal for a second phase of PAC. The present study aims to analyze comparatively the mobility and accessibility solutions contemplated by recent public policies,

${ }^{1}$ BRANDÃO, Rosana Gouveia; BONIFÁCIO, Isabela Mara da Silva Conceição; ALVES, Rosane Martins. Análise comparativa das soluções dos programas de governo para melhoria da mobilidade da Rocinha. In: II SIMPÓSIO NACIONAL DE GESTÃO E ENGENHARIA URBANA: SINGEURB, 2019, São Paulo. Anais... Porto Alegre: ANTAC, 2019. 
emphasizing the solutions of the cable car and the inclined plane. This analysis will be performed by comparing data of urban equipment and the use of ArcGIS tool, which allows the overlapping of indicators for a more complete evaluation of the proposed scenarios. According to the observations made, it can be concluded that the inclined planes show more adherence to the needs of the community.

Keywords: Rocinha, Mobility, PAC, Growth Acceleration Program.

\section{INTRODUÇÃO}

O processo de urbanização nas cidades brasileiras ocorreu de forma acelerada, desordenada e desigual, o que culminou no aparecimento dos assentamentos irregulares, com infraestrutura precária, localizados na maioria das vezes em regiões de aclive ou à beira de rios.

A favela da Rocinha, inicialmente, era uma área formal e regularizada - fazenda produtora de café e hortaliças. A migração nordestina e as obras de abertura dos Túneis Rebouças e Dois Irmãos deram início a ocupação irregular, sendo, após intenso crescimento, reconhecida como bairro, em 1993. As redes de infraestrutura, não acompanharam tal reconhecimento formal (MINISTÉRIO DAS CIDADES, 2010).

Este artigo apresenta uma análise comparativa dos efeitos da inserção de equipamentos previstos em programas de governo, principalmente referente a plano inclinado e teleférico. Para isso, foram explicitados e analisados os sistemas propostos utilizando o software ArcGIS.

\section{CONTEXTUALIZAÇÃO}

O Estatuto da Cidade surgiu nos anos 2000, reconhecendo e legitimando o direito fundamental à cidade e ao transporte para todos os cidadãos (ESTATUTO DA CIDADE, 2001). Em 2005, foi promovido pelo Governo do Estado, o Concurso Nacional de Ideias para Urbanização da Rocinha, tendo como vencedora a equipe coordenada pelo arquiteto Luiz Carlos de Menezes Toledo (TOLEDO, 2007), que posteriormente, com base num processo participativo, criou o Projeto Urbano da Rocinha (MAYERHOFER \& TOLEDO, 2007). Em 2008, as intervenções promovidas pelo poder público durante a fase 1 do PAC, tiveram como origem as propostas de Toledo (MINISTÉRIO DAS CIDADES, 2010). Contudo, em 2013, foi lançada a proposta do PAC 2, que abrange como tema principal a construção de um novo sistema de mobilidade, o Teleférico (BUSSINGER, 2015). Esse tem conceito distinto do proposto pelo Projeto Urbano da Rocinha, que tem como principal equipamento o plano inclinado.

O plano inclinado pode ser composto por uma ou mais cabinas alinhadas sobre um trilho e ligadas a cabos. Podem possuir compartimentos para cargas, que em alguns casos, são utilizados possibilitando contrapeso. Quando há necessidade de adaptação à topografia do terreno, é utilizada a tecnologia para inclinação variável, bem mais onerosa que inclinação constante. A estação de transbordo é uma solução para viabilizar a execução nesses casos. São implantados normalmente nas laterais dos territórios, para evitar a segmentação do tecido urbano, ou seja, perda da conectividade física e social dos residentes com o outro lado (SANTOS, 2014).

Já o teleférico é um equipamento de transporte aéreo por propulsão a cabo, normalmente utilizado em áreas com relevo acidentado e/ou de difícil acesso. Conta com estações/terminais, para operação e embarque/desembarque de passageiros, sistema de evacuação, altas torres, que apoiam os cabos, que por sua vez, mantêm as cabines suspensas e em funcionamento (SANTOS, 2014).

O comparativo dos equipamentos urbanos em relação aos programas que os contemplam encontra-se no Quadro 1. 
Quadro 1 - Comparativo entre equipamentos urbanos propostos para implantação na Rocinha

\begin{tabular}{|c|c|c|c|c|}
\hline EQUIPAMENTOS & $\begin{array}{l}\text { PLANO DIRETOR } \\
(2005-2008)\end{array}$ & $\begin{array}{c}\text { PAC 1 } \\
(2011-2014)\end{array}$ & $\begin{array}{c}\text { PAC } 2 \\
(2014-?)\end{array}$ & ANÁLISE \\
\hline NOVAS VIAS & Contemplado & Contemplado & Contemplado & $\begin{array}{l}\text { - Grande relevância } \\
\text { - Maior permeabilidade } \\
\text { - Chegada de outras redes } \\
\text { de infraestrutura }\end{array}$ \\
\hline ELEVADOR & $\begin{array}{c}\text { Não } \\
\text { contemplado }\end{array}$ & $\begin{array}{c}\text { Não } \\
\text { contemplado }\end{array}$ & Contemplado & $\begin{array}{l}\text { - Média relevância } \\
\text { - Trânsito em áreas com } \\
\text { cotas muito diferentes } \\
\text { - Alto nível de acessibilidade } \\
\text { - Complementa acesso a } \\
\text { outros equipamentos }\end{array}$ \\
\hline $\begin{array}{l}\text { ESCADAS } \\
\text { ROLANTES }\end{array}$ & $\begin{array}{c}\text { Não } \\
\text { contemplado }\end{array}$ & $\begin{array}{c}\text { Não } \\
\text { contemplado }\end{array}$ & Contemplado & $\begin{array}{l}\text { Média relevância } \\
\text { Acesso a áreas } \\
\text { localizadas em terreno } \\
\text { muito íngreme }\end{array}$ \\
\hline $\begin{array}{l}\text { SISTEMA DE } \\
\text { TELEFÉRICO }\end{array}$ & $\begin{array}{c}\text { Não } \\
\text { contemplado }\end{array}$ & $\begin{array}{c}\text { Não } \\
\text { contemplado }\end{array}$ & Contemplado & $\begin{array}{l}\text { - Grande relevância } \\
\text { - Acesso a áreas } \\
\text { localizadas em terreno } \\
\text { muito íngreme } \\
\text { - Maior velocidade de } \\
\text { operação se comparado } \\
\text { ao plano inclinado } \\
\text { - Risco de segregação e } \\
\text { mudança da dinâmica } \\
\text { social e econômica de } \\
\text { áreas centrais } \\
\text { - Risco de subutilização }\end{array}$ \\
\hline $\begin{array}{c}\text { PLANO } \\
\text { INCLINADO }\end{array}$ & Contemplado & $\begin{array}{l}\text { Contemplado, } \\
\text { mas não } \\
\text { executado }\end{array}$ & $\begin{array}{l}\text { Contemplado, } \\
\text { mas } \\
\text { modificado }\end{array}$ & $\begin{array}{l}\text { - Grande relevância } \\
\text { - Maior permeabilidade } \\
\text { sem comprometer a } \\
\text { dinâmica social existente } \\
\text { - Maior nível de } \\
\text { acessibilidade quando } \\
\text { comparado ao teleférico } \\
\text { - Protege áreas desabitadas } \\
\text { no entorno e utiliza } \\
\text { estrutura para rede de } \\
\text { drenagem } \\
\text { - Transporte de carga e } \\
\text { acesso de pessoas com } \\
\text { dificuldade de } \\
\text { locomoção }\end{array}$ \\
\hline
\end{tabular}

Fonte: Os autores

\section{METODOLOGIA}

Utilizando-se o software ArcGIS, foram compilados e compartilhados dados geográficos através de mapas elaborados com o posicionamento e traçado dos equipamentos de mobilidade, retirados de projetos dos Programas de Governo. Os indicadores inseridos foram levantados pelo Laboratório de Projetos Urbanos Sustentáveis (LabURB). Das funções/empresas identificadas (maioria informal em áreas de fácil acesso), o maior número é de comércio e venda de produtos $(76,15 \%)$, seguida das de prestação de serviços $(19,92 \%)$ e o restante de fábricas e indústrias (ROSSI, 2018).

Com My Maps do Google, foi realizado mapa de densidade construída com levantamento das habitações, obtendo-se 6.346 polígonos, com área total de $418.562,74 \mathrm{~m}^{2}$, dividida em 80 Setores Censitários, chegando-se ao percentual de ocupação do solo (ROSSI, 2018). 
No mapa de sistema viário, foram posicionados pontos de ônibus e mototáxi, e a estação do metrô. Para determinação dos pontos de mototáxi foram utilizadas informações do escritório ArquiTraço Projetos Ltda, observação in loco e o "Mapa Cultural da Rocinha", formado por moradores (ROSSI, 2018).

A análise dos parâmetros foi realizada por meio da sobreposição dos componentes mencionados, compatibilização das informações e verificação da maior eficiência do equipamento urbano. Foram utilizados três mapas: de Efetividade (relação entre densidade populacional e oferta de Transporte), de Acessibilidade (relação entre oferta de serviços/funções e oferta e acesso aos meios de transporte existentes e propostos) e de Interface (relação entre áreas ainda passíveis de serem ocupadas e localização dos meios de transporte existentes e propostos). Nos dois primeiros mapas, foi analisado o atendimento à população. No último, foram analisados limites e métodos construtivos dos sistemas.

Também foram analisados os parâmetros: custo, carga e capacidade.

\section{ANÁLISE E DISCUSSÃO}

O Plano Diretor da Rocinha considera a mobilidade nos espaços internos, quando propõe alargamento das vias "principais" e adequação de vielas e escadarias, proporcionando maior permeabilidade. O PAC se mostra compatível com tais diretrizes. Os projetos das escadas rolantes e elevador também, apesar de não contemplados no Plano Diretor, pois representam importante ponto de acessibilidade entre locais de difícil acesso, grande desnível, e permitiriam acesso a outras obras de infraestrutura do PAC.

No tocante ao sistema de teleférico (PAC 2), é o equipamento que mais se distancia das diretrizes do Plano Diretor. Em propostas semelhantes, os teleféricos não foram suficientes para garantir fluidez interna nem conseguiram integrar satisfatoriamente os modos já existentes (SANTOS, 2014).

Do cenário apresentado, foram avaliados planos inclinados e teleférico, com relação ao atendimento à população. Observa-se no Mapa de Efetividade (Figura 1) que as estações de ambos os equipamentos estão nas áreas mais densas, de maior ocupação ou em suas proximidades, o que melhora a mobilidade. Os dois sistemas integram áreas centrais, bem como tornam acessível o Parque Ecológico, além de apresentarem interligação com o sistema viário existente. O teleférico tem como diferencial ter ponto de partida, para ambos os trechos, na Estação Via Ápia, que é localizada no acesso principal da Rocinha, próxima a Estação de Metrô São Conrado (Linha 4) e a Autoestrada Lagoa-Barra, diferentemente dos planos inclinados, que iniciam de pontos estratégicos internos ao bairro. O plano inclinado 1 , na parte inferior do mapa, atenderia a um público diferente do contemplado pelo teleférico e pelos planos inclinados 2 e 3 , evidenciando que esta obra deveria ser realizada em qualquer uma das hipóteses escolhidas. 
Figura 1 - Mapa de Efetividade. Relação entre a densidade populacional e a oferta de Transporte.

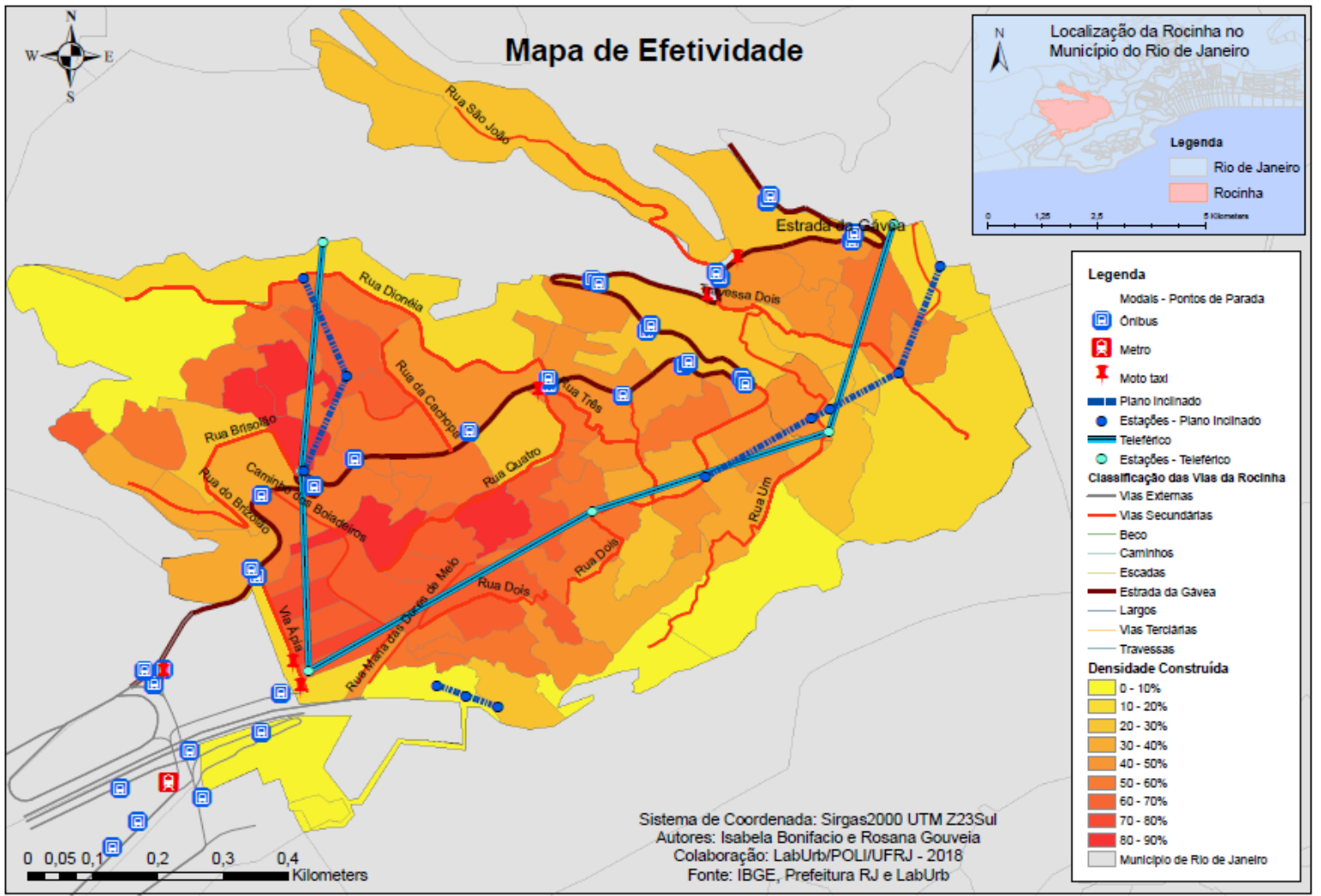

Fonte: Mapa gerado pelo software ArcGIS pelas autoras (2018)

Ainda com relação ao atendimento à população, foi utilizado o Mapa de Acessibilidade (Figura 2), em que foi observado que as estações foram posicionadas em centralidades que apresentam funções disponíveis, interações da comunidade local e integração com a malha viária e com os meios já utilizados, como vans e mototáxis. A construção das estações nessas localidades também permitiria maior permeabilidade das funções, tornando esses locais mais acessíveis e possibilitando o desenvolvimento de novas atividades. 
Figura 2 - Mapa de Acessibilidade. Relação entre a oferta de serviços e a oferta e acesso aos meios de transporte existentes e propostos.

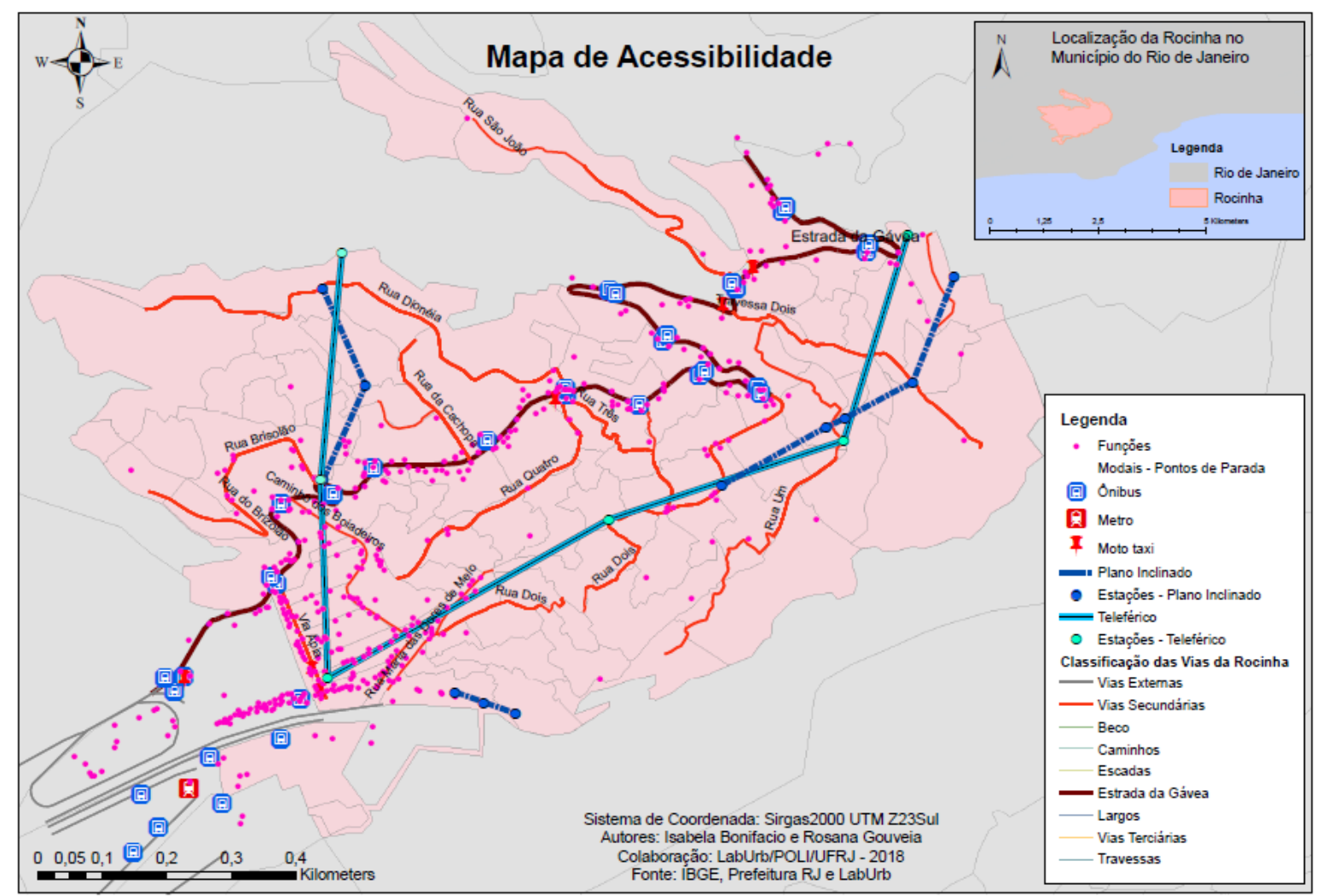

Fonte: Mapa gerado pelo software ArcGIS pelas autoras (2018)

A implantação de uma estação pode gerar segregação da malha bem como alteração da dinâmica local devido à grande quantidade de desapropriações. Para verificar o equipamento que seria menos prejudicial neste sentido, foi elaborado o Mapa de Interface (Figura 3). Notou-se que houve uma preocupação em alocar a maior parte das estações em áreas pouco ou não edificadas. 
Figura 3: Mapa de Interface. Relação entre áreas ainda passíveis de serem ocupadas e localização dos meios de transporte existentes e propostos.

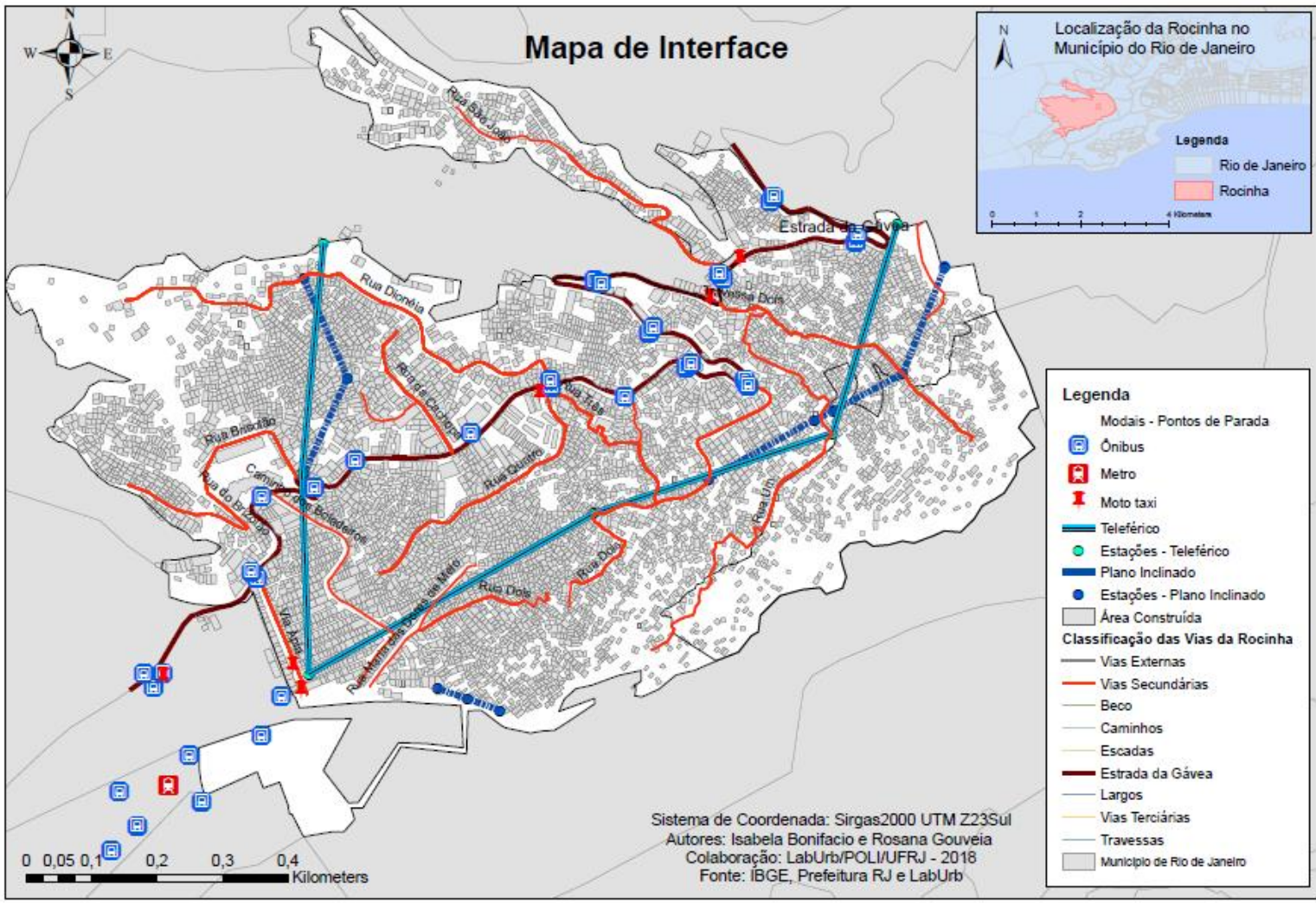

Fonte: Mapa gerado pelo software ArcGIS pelas autoras (2018)

Para os planos inclinados, buscou-se minimizar as desapropriações para construção do percurso, fazendo com que passasse por áreas em talvegues, que já causam ruptura natural no tecido, ou áreas de alto risco, com potencial de desabamento e foco de doenças. Na estrutura de apoio, podem ser instaladas escadas de drenagem. Suas estações apresentam simplicidade nas instalações, não demandando grandes esforços nem gastos para construção. O projeto contempla maior número de estações, inseridas onde já existe interação da comunidade, diminuindo deslocamentos a pé e interrupção nos fluxos de pedestres pela segregação da malha (BUSSINGER, 2015).

Para o teleférico, é necessário área muito ampla de desapropriação, tanto no entorno das estações, quanto em ruas, para chegada do maquinário para montagem das estruturas metálicas de grande porte, possibilitando grande alteração na dinâmica local (BUSSINGER, 2015).

Com relação ao custo, o do teleférico é mais alto que o do plano inclinado, pois sua estrutura é mais robusta. Peças para composição e reposição são importadas, fazendo com que instalação e manutenção fiquem a mercê de variações cambiais. O valor orçado para a implantação é de quase metade do valor total do PAC 2 (SANTOS, 2014).

Outros aspectos analisados: capacidade e tipos de carga. Apesar de o teleférico ter capacidade inferior por cabine - 8 passageiros contra 25 do plano inclinado - apresenta menor tempo de trajeto até a última estação, por não fazer pausas. Como a frequência de passagem pela estação também é maior, pois conta com várias cabines, essa seria a melhor solução. Porém, o plano inclinado, além de transportar maior número de pessoas, permite transporte de cargas, de pessoas idosas e com dificuldade de locomoção, visto que ocorrem paradas nas estações (BUSSINGER, 2015). 


\section{CONCLUSÕES}

Avaliando todo o contexto, o ideal seria que o Plano Socioespacial da Rocinha fosse seguido o mais fidedignamente possível porque, além de atender aos anseios e necessidades da comunidade, proporcionaria um sistema de transportes mais ramificado, aumentando seu alcance e sua efetividade. Os planos inclinados foram localizados nos projetos em pontos importantes, apresentam menor custo de implantação e manutenção e possibilidade de transporte de todos os moradores e cargas, o que faz dessa solução a melhor apresentada.

\section{AGRADECIMENTOS}

Ao LabURB - Laboratório de Projetos Urbanos Sustentáveis, (Programa de Pós-Graduação em Engenharia Urbana da Escola Politécnica da UFRJ), pela contribuição.

\section{REFERÊNCIAS}

BRASIL. Estatuto da Cidade - Lei n. 10257, de 10 de julho de 2001. Regulamenta os arts. 182 e 183 da Constituição Federal, estabelece diretrizes gerais da política urbana e dá outras providências. Diário Oficial da União. Brasília, DF, 10 jul. 2001. Disponível em:

<http://www.planalto.gov.br/ccivil_03/leis/leis_2001/110257.htm>. Acesso em: 13 abr. 2018.

BUSSINGER, B. Mobilidade na Rocinha - Uma solução para o Plano Inclinado. Trabalho de conclusão de curso de arquitetura e urbanismo. PUC - RIO, Rio de Janeiro, RJ, 2015.

MAYERHOFER \& TOLEDO, SECRETARIA ESTADUAL DE OBRAS (SEO), EMPRESA DE OBRAS PÚBLICAS (EMOP). Plano Diretor Socio-espacial da Rocinha. Rio de Janeiro: MAYERHOFER \& TOLEDO, 2007.

MINISTÉRIO DAS CIDADES, SECRETARIA NACIONAL DE HABITAÇÃO. Urbanização de Favelas: a experiência do PAC. Brasília: MINISTÉRIO DAS CIDADES, 2010.

ROSSI, A. M. G.; BARBOSA, G. S.; CORRÊA, R. M.; ESSER, B. C.; MACHADO, G. W.; MORAIS, B. U. Análise ambiental, social e urbana de um sistema complexo: Comunidade da Rocinha, Rio de Janeiro. In: CONGRESSO PNUM 2018, Porto, Portugal, 2018.

\section{SANTOS, L. B. D. Impactos da Implantação do Teleférico como Sistema de Transporte nas}

Favelas: O Caso do Complexo do Alemão. Dissertação de Mestrado apresentada à PUC-Rio. Rio de Janeiro, 2014.

SANTOS, L. B. D. Mobilidade urbana nas favelas do Rio de Janeiro: Intervenções e impactos sociais. In: XVI ENCONTRO REGIONAL DE HISTÓRIA DA ANPUH-RIO: SABERES E PRÁTICAS CIENTÍfICAS, 2014, Rio de Janeiro. Anais... Rio de Janeiro: USU/FIOCRUZ, 2014.

TOLEDO, L. C.; SILVA, J. M. P.; TÂNGARI, V. R. Derrubando os Muros: Planejamento participativo e integração social na comunidade da Rocinha no Rio de Janeiro. In: XII ENCONTRO NACIONAL DA ANPUR, Belém - PA, 2007. 